\title{
Iranian EFL Learners' Perceptions with Respect to Tasks in Comparison with the Actual Content of the Textbooks*
}

\author{
Mohsen Sa'di Khosroshahi \\ University of Tabriz, Tabriz, Iran \\ Farahman Farrokhi \\ English Department, University of Tabriz, Tabriz, Iran
}

\begin{abstract}
Most of the studies in the field of textbook evaluation in Iran have evaluated the textbooks from the perspective of teachers and have ignored the perceptions of the learners. The purpose of this study was to shed some light on the perceptions of Iranian EFL learners towards tasks and to compare their perceptions with the actual content of their textbooks. To this end, the study employed a descriptive and survey-based design. A questionnaire consisting of two different sections was distributed among 100 first-year high school students in four schools. One class in each school participated in the study. The first-year high school English textbook was carefully analyzed with respect to the percentages of tasks and non-tasks. The results of the questionnaire analysis were then compared to the results of the content analysis of the textbook. The comparison showed that the students generally rated tasks as being highly effective in the learning of English. In contrast, in their actual textbook, there was a much less number of these sorts of communicative activities. These findings show that there are wide gaps between the Iranian learners' perceptions and the actual content of their textbooks. These findings can be used by the textbook designers in order to take account of the learners' preferences and perceptions while designing new editions of textbooks.
\end{abstract}

Index Terms - textbook, textbook evaluation, task, motivation, EFL learners

\section{INTRODUCTION}

Most of the textbook evaluations so far undertaken have been from the point of view of teachers to the exclusion of the viewpoints, needs, perceptions, and preferences of the learners who constitute the majority of the textbook consumers and whose interest and motivation are necessary for the successful achievement of the course goals. A quick glancing at high school English textbooks used in Iranian schools will reveal the fact that they lack a crucial component for getting students actively engaged in communication; namely tasks. While the textbooks certainly include a number of tasks, it does not seem to be enough to enable the students to be motivated enough to learn a foreign language, that which they usually treat as being something that is detached from the reality of their lives and as a puzzle solving task mainly involving the decoding of linguistic elements in a myriad of exercises that hopelessly attempt to make them masters of abstract grammatical rules without presenting them with enough examples of the actual language use.

\section{REVIEW OF THE RELATED LITERATURE}

\section{A. The Importance of Textbooks in Language Learning}

Of the various instructional materials, textbooks are the ones that are widely used in language classrooms. Textbooks are considered as being important sources for teachers in assisting students to learn various subject matters including English. They are seen as foundational elements of school instruction and the main source of information for teachers. Textbooks in Iran provide the basis for the large share of the language input learners receive as well as the language practice in the classroom. In fact, for EFL learners textbooks are the primary source of first-hand experience with the target language (Azizifar et al., 2010). Textbooks play a major role in ELT classes in the actualization of the plans and decisions into useful materials, tasks and activities. (Azizifar et al., 2010; Kirkgöz, 2009; Richards, 2001, as cited in Amiryousefi \& Ketabi, 2011)

\section{B. Textbook Evaluation}

According to Tomlinson et al. (2001) textbook evaluation is an activity in the field of applied linguistics that enables teachers, supervisors, administrators and materials developers to make judgments about the effect the materials have on

\footnotetext{
* It is to be noted that this study is based upon the M.A. thesis of the first author to be presented at the University of Tabriz.
} 
the people who use them. McGrath (2002) believes that textbook evaluation is of paramount importance for the development and administration of language learning programs.

\section{The Role of Tasks in Promoting Intrinsic Motivation}

A more recent offshoot of Maslow's view of motivation is the effect of flow on ultimate attainment in Csikszentmihalyi's "flow theory". Csikszentmihalyi (1975, as cited in Brown, 2006) proposed flow theory to better understand motivation. Flow is a type of intrinsic motivation (Liao, 2006). Csikszentmihalyi defines flow as "the state in which people are so involved in an activity that nothing else seems to matter; the experience itself is so enjoyable that people will do it even at great cost, for the sheer sake of doing it" (Csikszentmihalyi, 1991, p. 4).

The psychological conditions that make the flow experience possible include:

1. Individuals usually experience flow when they are engaged in tasks that they have a chance of completing.

2. They must be able to concentrate on the task in hand.

3. The task has clear goals, which makes concentration possible.

4. The provision of immediate feedback by the task, also, makes concentration possible. 5. Engagement in an enjoyable activity leaves no room for troubling thoughts.

6. Enjoyable experiences allow people to exercise a sense of control over their actions.

7. Self-consciousness and concern for self disappear, yet the sense of self emerges stronger after the flow experience is over.

8. The sense of duration of time is altered; hours may seem like seconds (Csikszentmihalyi, 1991).

Clear goals and immediate feedback allow individuals know when they have succeeded at the performance of the task (Dietz, 2004). Students who experience flow learn better, so it is important to investigate how flow experience can be achieved by EFL learners. Students could be given language tasks at their appropriate level (condition number 1), and be allowed to complete the tasks without excessive intervention from the teacher's side or without much restriction (condition 2). These learning tasks could be clearly scaffolded by the teacher (condition 3), and evaluation and achievement could be assessed by the learners and their peers in terms of the outcome of the task (e.g. language performance, presentation, report, etc.), Skehan's (1996, as cited in Nassaji, H. \& Fotos, 2010) definition of 'task' bears some similarities with Csikszentmihalyi's first four conditions:

A task is an activity in which: 1) The primary focus is on meaning rather than on form; 2) The task is related in some way to real world tasks and bears some resemblance to how language is used in real life; 3) the completion of the task has some priority; and 4) the task performance is assessed in terms of the outcomes of the task.

Condition 5 promotes effortless involvement that takes one's mind off the worries of everyday life. Teachers can try to fulfill condition 5 by using language-learning projects, which encourage meaningful development and use of language skills. Condition 6 encourages engaging students in learning experiences that are enjoyable to them. Condition 7 refers to the importance of language learning through group work and collaboration. Finally, condition 8 suggests that students should be allowed to be immersed in an enjoyable learning task for as long as they see it fit, rather than being told for example "You have five minutes to complete this activity." The application of these 8 conditions in EFL classrooms and allowing the learners to experience flow could lead learners at all levels to perform meaningful and enjoyable language learning tasks to the best of their abilities, which would in effect lead to them seeing languagelearning as an enjoyable, voluntary, and worthwhile activity (Finch, 2007). The present study seeks to answer the following questions:

Research Question 1: How effective are tasks in the learning of English from the perspective of Iranian high school students?

Research Question 2: How effective are the actual textbook activities in the learning of English from the perspective of Iranian high school students?

Research Question 3: What is the percentage of tasks and non-tasks in Iranian high school textbooks?

\section{METHODOLOGY}

\section{A. Participants}

A total of 100 language learners with their age ranging from 15-16 participated in this study. The participants had a bilingual background of Turkish and Persian. All 100 participants were male and they were all first-year high school students. The participants were chosen from four high schools.

\section{B. Design of the Study}

This study employed a descriptive, survey-based design. The study was conducted through distributing a translated version of the questionnaire in Persian, which included questions that offered the participants various samples of tasks that can be used in their textbooks and by their teachers in the classroom. The participants were asked to state their preferences by answering Likert-type items in the questionnaire. Afterwards, the first-year high school English textbook was analyzed. The results of the textbook analysis were compared to the preferences and perceptions of the first-year high school students in order to find out the mismatches between their preferences and the actual content of their textbook. 


\section{Materials}

The materials used in this study included a questionnaire that was divided into two parts. The first part presented the students with five samples of tasks, two focused tasks, two unfocused tasks, and one reading task. The listening task was not included because the researcher intended to present the students with tasks that could be performed in Iranian high schools in their present state, and most high schools do not have the luxury of providing teachers with audio tapes. 10 questions followed the sample tasks to provide the students with the opportunity to state their attitudes towards tasks by answering Likert-type questions each of which had five options to choose from; namely, Highly effective somewhat effective - I do not know - somewhat ineffective - highly ineffective. The second part of the questionnaire constituted 10 Likert-type questions, which were intended to elicit their attitudes towards the actual content of their textbook.

\section{Procedures}

After obtaining the necessary permissions from the Ministry of Education and also from the principals of the schools and the teachers, the questionnaires were distributed in four classes. No specific criteria were used in the selection of the schools and the classes that participated in this study. The first version of the questionnaire was pilot-tested with 15 participants that were similar in their characteristics to the ones that participated in the main research. After making the necessary changes, the second version of the questionnaire was pilot-tested with 25 students from another high school. The initial results were satisfactory, and the second version was distributed among the participants from three other schools.

After the completion of the questionnaire analysis, the first-year high school textbook was also analyzed in terms of the number of items allocated to tasks. The percentages of tasks and non-tasks in each section of the textbook and in the textbook as a whole were calculated. In order to distinguish between tasks and non-tasks five criteria were used:

1. A task is a workplan, which constitutes a plan for learner activity.

2. The primary focus of a task is on meaning.

3. The performance of a task involves real-world processes of language use.

4. Any of the four language skills can be used in a task.

5. A task engages cognitive processes (Ellis, 2003).

Finally, the results obtained from the analysis of the questionnaire were compared to the results of the textbook analysis. The results of the data analysis were checked by another coder and the inter-rater reliability turned out to be $95 \%$.

\section{Data Analysis \& Results}

\section{A. Descriptive Statistics for Research Question 1}

The results of the first 10 questions in the questionnaire, which represent the first macro-category; i.e. "the effectiveness of tasks in language learning from learners' perspective" are demonstrated in Table 1.

TABLE 1:

\begin{tabular}{|c|c|c|c|c|c|}
\hline & Highly effective & Somewhat effective & I do not know & Somewhat ineffective & Highly ineffective \\
\hline 1 & \multicolumn{5}{|c|}{ How effective can such tasks be in making language learning enjoyable? } \\
\hline & 31 & 55 & 7 & 4 & 3 \\
\hline 2 & \multicolumn{5}{|c|}{ How effective can such tasks be in engaging you in learning English? } \\
\hline & 37 & 37 & 14 & 8 & 4 \\
\hline 3 & \multicolumn{5}{|c|}{ How effective can such tasks be in increasing your motivation to learn English? } \\
\hline & 36 & 44 & 11 & 5 & 4 \\
\hline 4 & \multicolumn{5}{|c|}{ How effective can such tasks be in causing you to cooperate with your group members to perform the task? } \\
\hline & 35 & 35 & 16 & 11 & 3 \\
\hline 5 & \multicolumn{5}{|c|}{ How effective can such tasks be in improving your accuracy in producing grammatically correct sentences? } \\
\hline & 40 & 45 & 10 & 4 & 1 \\
\hline 6 & \multicolumn{5}{|c|}{ How effective can such tasks be in improving your fluency in speaking English? } \\
\hline & 55 & 28 & 11 & 4 & 2 \\
\hline 7 & \multicolumn{5}{|c|}{ How effective can such tasks be in improving your vocabulary knowledge? } \\
\hline & 38 & 39 & 16 & 6 & 1 \\
\hline 8 & \multicolumn{5}{|c|}{ How effective can such tasks be in improving your pronunciation? } \\
\hline & 39 & 44 & 9 & 6 & 2 \\
\hline 9 & \multicolumn{5}{|c|}{ How effective can such tasks be in improving your language skills (reading, writing, listening, speaking)? } \\
\hline & 58 & 29 & 7 & 4 & 2 \\
\hline 10 & \multicolumn{5}{|c|}{ How effective can such tasks be in providing you with the opportunity to communicate with others? } \\
\hline & 43 & 39 & \begin{tabular}{|l|}
8 \\
\end{tabular} & 6 & 4 \\
\hline
\end{tabular}

As Table 1 shows, most of the students' responses have a tendency towards the effective end of the continuum. The number of responses rating tasks as effective is significantly higher than those rating them as ineffective. Table 2 presents the percentages for questions 1-10 in the questionnaire. 
TABLE 2:

THE PERCENT AGES FOR QUESTIONS 1-10 IN THE QUESTIONNAIRE

\begin{tabular}{|l|l|l|l|l|}
\hline Highly effective & Somewhat effective & I do not know & Somewhat ineffective & Highly ineffective \\
\hline The Total Number of the Selected Options & 109 & 58 & 26 \\
\hline 412 & 395 & $10.9 \%$ & $5.8 \%$ & $2.6 \%$ \\
\hline The Percentage of the Selected Options & $39.5 \%$ & $8.4 \%$ \\
\hline $41.2 \%$ & $10.9 \%$ & \\
\hline The Merging of the Percentages of the Selected Options & \\
\hline $80.7 \%$
\end{tabular}

The first row of Table 2 presents the sum of the number of responses to each of the five choices in questions 1-10. Table 2 shows that there are 412 "highly effective" choices and 395 "somewhat effective" choices, the numbers of which are significantly higher than the numbers of "highly ineffective" (26) and "somewhat ineffective" (58) choices. Thus, the percentages of the responses rating tasks to be effective $(80.7 \%)$ are significantly higher than the percentages of those that rated them to be ineffective (8.4\%). The results of the analysis of the first 10 questions in the questionnaire are demonstrated in Fig. 1, illustrates the results in the third row of Table 2, in which the percentages in the second row of Table 2 have been merged.

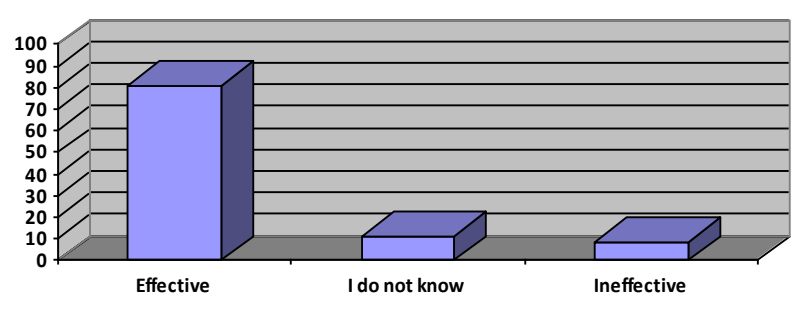

Figure 1.The results of the analysis of questions 1-10 in the questionnaire

Table 2 and Fig. 1, show that $80.7 \%$ of the responses considered tasks to be effective in the learning of English and $8.4 \%$ of the responses rated them as being ineffective. $10.9 \%$ of the responses were indeterminate.

\section{B. Descriptive Statistics for Research Question 2}

The results of the questions 11-20, which represent the second macro-category; i.e. the effectiveness of textbook activities in language learning from learners' perspective" are presented in Table 3.

TABLE 3:

THE RESULTS OF THE ANALYSIS OF QUESTIONS 11-20 IN THE QUESTIONNAIRE

\begin{tabular}{|c|c|c|c|c|c|}
\hline & Highly effective & Somewhat effective & I do not know & Somewhat ineffective & Highly ineffective \\
\hline 11 & \multicolumn{5}{|c|}{ How effective are the actual activities in your textbook in making language learning enjoyable? } \\
\hline & 3 & 11 & 11 & 45 & 30 \\
\hline 12 & \multicolumn{5}{|c|}{ How effective are the actual activities in your textbook in engaging you in learning English? } \\
\hline & 3 & 14 & 27 & 32 & 24 \\
\hline 13 & \multicolumn{5}{|c|}{ How effective are the actual activities in your textbook in increasing your motivation to learn English? } \\
\hline & 2 & 15 & 21 & 30 & 32 \\
\hline 14 & \multicolumn{5}{|c|}{ How effective are the actual activities in your textbook in encouraging you to work in groups? } \\
\hline & 1 & 9 & 12 & 30 & 48 \\
\hline 15 & \multicolumn{5}{|c|}{ How effective are the actual activities in your textbook in improving your accuracy in producing grammatically correct sentences? } \\
\hline & 3 & 26 & 19 & 32 & 20 \\
\hline 16 & \multicolumn{5}{|c|}{ How effective are the actual activities in your textbook in improving your fluency in speaking English? } \\
\hline & 6 & 15 & 11 & 28 & 40 \\
\hline 17 & \multicolumn{5}{|c|}{ How effective are the actual activities in your textbook in improving your vocabulary knowledge? } \\
\hline & 4 & 34 & 22 & 22 & 18 \\
\hline 18 & \multicolumn{5}{|c|}{ How effective are the actual activities in your textbook in improving your pronunciation? } \\
\hline & 2 & 24 & 17 & 28 & 29 \\
\hline 19 & \multicolumn{5}{|c|}{ How effective are the actual activities in your textbook in improving your language skills (reading, writing, listening, speaking)? } \\
\hline & 4 & 21 & 19 & 34 & 22 \\
\hline 20 & \multicolumn{5}{|c|}{ How effective are the actual activities in your textbook in providing you with the opportunity to communicate with others? } \\
\hline & 2 & 8 & 7 & 30 & 53 \\
\hline
\end{tabular}

As it is shown in Table 3, most of the students' responses tend towards the ineffective end of the continuum. The number of the responses rating the actual activities in the textbook as ineffective is significantly higher than those rating them as effective. Table 4 presents the percentages for questions 11-20 in the questionnaire. 
TABLE 4:

THE PERCENT AGES FOR QUESTIONS 11-20 IN THE QUESTIONNAIRE

\begin{tabular}{|c|c|c|c|c|}
\hline Highly effective & Somewhat effective & I do not know & Somewhat ineffective & Highly ineffective \\
\hline \multicolumn{5}{|c|}{ The Total Number of the Selected Options } \\
\hline 30 & 177 & 166 & 311 & 316 \\
\hline \multicolumn{5}{|c|}{ The Percentage of the Selected Options } \\
\hline $3 \%$ & $17.7 \%$ & $16.6 \%$ & $31.1 \%$ & $31.6 \%$ \\
\hline \multicolumn{5}{|c|}{ The Merging of the Percentages of the Selected Options } \\
\hline $20.7 \%$ & & $16.6 \%$ & $62.7 \%$ & \\
\hline
\end{tabular}

The first row of Table 4 presents the sum of the number of responses to each of the five choices in questions 11-20. As Table 4 shows, the percentages of the responses rating the actual textbook activities to be ineffective $(62.7 \%)$ are significantly higher than the percentages of those that rated them to be effective $(20.7 \%)$. The results of the analysis of questions 11-20 in the questionnaire are demonstrated in Fig. 2. Fig.2, illustrates the results in the third row of Table 4 which merges the percentages in the second row of Table 4.

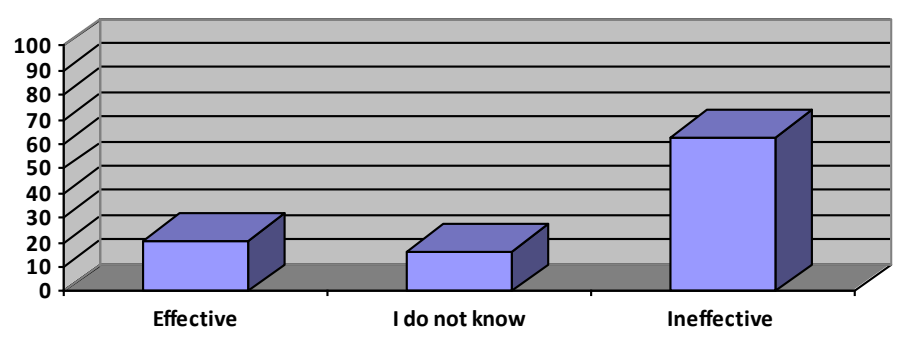

Figure 2.The results of the analysis of questions 11-20 in the questionnaire

As it is evident from both Table 4 and Fig. 2, only $20.7 \%$ of the responses rated the actual activities in the textbook as being effective. $62.7 \%$ of the responses rated them as being ineffective, and $16.6 \%$ of the responses were indeterminate.

Above, the results of the questionnaire were presented in various charts and figures. What will follow is a careful analysis of different sections of the first-year high school English textbook in order to determine the number and percentages of tasks and non-tasks in each section.

\section{Descriptive Statistics for Research Question 3}

Table 5 presents the number of tasks and non-tasks in the Section A of the textbook (The New Words Section).

TABLE 5:

THE NUMBER OF TASKS AND NON-TASKS IN SECTION A

\begin{tabular}{|l|l|l|l|}
\hline & Non-Task & Total \\
\hline Lesson & $\begin{array}{l}\text { The Number of Items With Sample } \\
\text { Sentences }\end{array}$ & $\begin{array}{l}\text { The Number of "Practice Your New } \\
\text { Words" Items }\end{array}$ & Tour| \\
\hline One & 8 & 5 & 13 \\
\hline Two & 10 & 5 & 15 \\
\hline Three & 7 & 6 & 14 \\
\hline Four & 7 & 5 & 12 \\
\hline Five & 6 & 5 & 11 \\
\hline Six & 8 & 6 & 14 \\
\hline Seven & 6 & 7 & 13 \\
\hline Eight & 8 & 5 & 13 \\
\hline Nine & 8 & 5 & 13 \\
\hline Sum & & & $\mathbf{1 1 8}$ \\
\hline
\end{tabular}

As Table 5 shows, there is a total number of 118 items in Section A, all of which fall into the category of non-tasks. Table 6 presents the percentages of tasks and non-tasks in the Section A of the textbook (The New Words Section).

TABLE 6:

THE PERCENTAGES OF TASKS AND NON-TASKS IN SECTION

\begin{tabular}{|l|l|}
\hline The Percentage of Non-Tasks in Section A & $100 \%$ \\
\hline The Percentage of Tasks in Section A & $0 \%$ \\
\hline
\end{tabular}

Table 7 presents the different types of activities and the numbers of tasks and non-tasks in the Section $\mathrm{C}$ of the textbook (The Comprehension Section). 
TABLE 7:

THE NUMBER OF TASKS AND NON-TASKS IN SECTION C

\begin{tabular}{|c|c|c|c|c|c|}
\hline \multirow[b]{2}{*}{ Lesson } & \multicolumn{4}{|l|}{ Task } & \multirow[b]{2}{*}{ Total } \\
\hline & $\begin{array}{l}\text { Answering Questions } \\
\text { Orally }\end{array}$ & True or False & Multiple Choice & $\begin{array}{l}\text { Sentence } \\
\text { Completion }\end{array}$ & \\
\hline One & 6 & 5 & 5 & 6 & 24 \\
\hline Two & 7 & 6 & 5 & 5 & 24 \\
\hline Three & 6 & 5 & 5 & 7 & 23 \\
\hline Four & 7 & 8 & 4 & 0 & 19 \\
\hline Five & 8 & 6 & 4 & 0 & 18 \\
\hline Six & 6 & 5 & 4 & 0 & 15 \\
\hline Seven & 6 & 5 & 4 & 0 & 15 \\
\hline Eight & 8 & 5 & 5 & 7 & 25 \\
\hline Nine & 7 & 8 & 4 & 0 & 19 \\
\hline Sum & & & & & 182 \\
\hline
\end{tabular}

Table 8 shows that there are 182 items in Section $\mathrm{C}$, all of which fulfill the necessary criteria to be considered reading tasks. Table 8 presents the percentages of tasks and non-tasks in the Section $\mathrm{C}$ of the textbook (The Comprehension Section).

TABLE 8:

THE PERCENTAGES OF TASKS AND NON-TASKS IN SECTION C

\begin{tabular}{|l|l|}
\hline \multicolumn{1}{|c|}{ The Percentage of Non-Tasks in Section C } & $0 \%$ \\
\hline The Percentage of Tasks in Section C & $100 \%$ \\
\hline
\end{tabular}

Table 9 presents the number of tasks and non-tasks in the Section D of the textbook (The Speak Out Section).

TABLE 9:

THE NUMBER OF TASKS AND NON-TASKS IN SECTION D

\begin{tabular}{|c|c|c|c|c|c|c|c|c|}
\hline Lesson & $\begin{array}{l}\text { Substitution } \\
\text { Drill }\end{array}$ & Listening & Repetition & $\begin{array}{l}\text { Answering } \\
\text { Questions } \\
\end{array}$ & $\begin{array}{l}\text { Sentence } \\
\text { Completion } \\
\end{array}$ & $\begin{array}{l}\text { Making New } \\
\text { Sentences } \\
\end{array}$ & Task & Total \\
\hline One & 18 & 0 & 0 & 8 & 0 & 15 & 0 & 41 \\
\hline Two & 7 & 0 & 0 & 8 & 0 & 9 & 10 & 34 \\
\hline Three & 18 & 0 & 12 & 0 & 0 & 10 & 0 & 40 \\
\hline Four & 15 & 0 & 10 & 0 & 0 & 20 & 0 & 45 \\
\hline Five & 10 & 2 & 0 & 5 & 0 & 10 & 0 & 27 \\
\hline Six & 0 & 0 & 12 & 0 & 0 & 10 & 0 & 22 \\
\hline Seven & 14 & 0 & 0 & 0 & 0 & 14 & 6 & 34 \\
\hline Eight & 9 & 0 & 0 & 14 & 0 & 13 & 0 & 36 \\
\hline Nine & 12 & 0 & 10 & 13 & 8 & 18 & 0 & 61 \\
\hline Sum & & & & & & & 16 & 340 \\
\hline
\end{tabular}

Table 9 shows that out of a total of 340 items in Section D, only 16 items can be classified as tasks. The percentages of tasks and non-tasks in the Section D of the textbook (The Speak Out Section) are presented in Table 10.

TABLE 10:

THE PERCENTAGES OF TASKS AND NON-TASKS IN SECTION D

\begin{tabular}{|l|l|}
\hline The Percentage of Non-Tasks in Section D & $95.1 \%$ \\
\hline The Percentage of Tasks in Section D & $4.9 \%$ \\
\hline
\end{tabular}

Table 11 presents the number of tasks and non-tasks in the Section E of the textbook (The Write It Down Section). 
TABLE 11:

THE NUMBER OF TASKS AND NON-TASKS IN SECTION E

\begin{tabular}{|c|c|c|c|c|c|c|}
\hline Lesson & Writing & Non-Task & Task & Total & $\begin{array}{l}\text { Total Number of } \\
\text { Non-Tasks }\end{array}$ & $\begin{array}{l}\text { Total Number of } \\
\text { Tasks }\end{array}$ \\
\hline \multirow[t]{2}{*}{ One } & Writing 1 & & Task & 5 & 0 & 5 \\
\hline & Writing 2 & & Task & 5 & 0 & 5 \\
\hline \multirow[t]{2}{*}{ Two } & Writing 1 & & Task & 5 & 0 & 5 \\
\hline & Writing 2 & Non-Task & & 8 & 8 & 0 \\
\hline \multirow[t]{2}{*}{ Three } & Writing 1 & Non-Task & & 8 & 8 & 0 \\
\hline & Writing 2 & Non-Task & & 5 & 5 & 0 \\
\hline \multirow{3}{*}{ Four } & Writing 1 & Non-Task & & 5 & 5 & 0 \\
\hline & Writing 2 & Non-Task & & 5 & 5 & 0 \\
\hline & Writing 3 & Non-Task & & 6 & 6 & 0 \\
\hline \multirow[t]{2}{*}{ Five } & Writing 1 & Non-Task & & 12 & 12 & 0 \\
\hline & Writing 2 & Non-Task & & 5 & 5 & 0 \\
\hline \multirow[t]{2}{*}{ Six } & Writing 1 & Non-Task & & 6 & 6 & 0 \\
\hline & Writing 2 & Non-Task & & 8 & 8 & 0 \\
\hline \multirow[t]{2}{*}{ Seven } & Writing 1 & & Task & 5 & 0 & 5 \\
\hline & Writing 2 & & Task & 7 & 0 & 7 \\
\hline \multirow{3}{*}{ Eight } & Writing 1 & Non-Task & & 6 & 6 & 0 \\
\hline & Writing 2 & Non-Task & & 5 & 5 & 0 \\
\hline & Writing 3 & Non-Task & & 6 & 6 & 0 \\
\hline \multirow{4}{*}{ Nine } & Writing 1 & Non-Task & & 5 & 5 & 0 \\
\hline & Writing 2 & Non-Task & & 5 & 5 & 0 \\
\hline & Writing 3 & Task & & 10 & 0 & 10 \\
\hline & Writing 4 & Non-Task & & 10 & 10 & 0 \\
\hline Sum & & & & 142 & 105 & 37 \\
\hline
\end{tabular}

As it is shown in Table 11, out of a total of 142 items in Section E, only 37 items can be classified as tasks, while a large number of them (105 items) cannot be considered as tasks. The percentages of tasks and non-tasks in the Section E of the textbook (The Write It Down Section) are demonstrated in Table 12.

TABLE 12:

THE PERCENTAGES OF TASKS AND NON-TASKS IN SECTION E

\begin{tabular}{|l|l|}
\hline The Percentage of Non-Tasks in Section E & $73 \%$ \\
\hline The Percentage of Tasks in Section E & $26 \%$ \\
\hline
\end{tabular}

Table 13 presents the number of tasks and non-tasks in the Section F of the textbook (The Language Functions Section).

TABLE 13:

THE NUMBER OF TASKS AND NON-TASKS IN SECTION F

\begin{tabular}{|l|l|l|l|}
\hline Lesson & Non-Task & Task & Total \\
\hline One & 0 & 1 & 1 \\
\hline Two & 0 & 1 & 1 \\
\hline Three & 0 & 1 & 1 \\
\hline Four & 5 & 1 & 6 \\
\hline Five & 0 & 5 & 5 \\
\hline Six & 0 & 1 & 1 \\
\hline Seven & 0 & 1 & 1 \\
\hline Eight & 0 & 1 & 1 \\
\hline Nine & 0 & 1 & 1 \\
\hline Sum & $\mathbf{5}$ & $\mathbf{1 3}$ & $\mathbf{1 8}$ \\
\hline
\end{tabular}

Table 13 shows that out of a total of 18 items in Section F, most of them (13 items) are tasks and only a few of them (5 items) are non-tasks. The percentages of tasks and non-tasks in the Section F of the textbook (The Language Functions Section) are presented in Table 14.

TABLE 14:

THE PERCENTAGES OF TASKS AND NON-TASKS IN SECTION F

\begin{tabular}{|l|l|}
\hline The Percentage of Non-Tasks in Section F & $27.7 \%$ \\
\hline The Percentage of Tasks in Section F & $72.2 \%$ \\
\hline
\end{tabular}

The number of tasks and non-tasks in the Section $G$ of the textbook (The Pronunciation Section) is presented in Table15. 
TABLE 15:

THE NUMBER OF TASKS AND NON-TASKS IN SECTION G

\begin{tabular}{|c|c|c|c|c|}
\hline Lesson & Item Number & Non-Task & Task & Total \\
\hline \multirow[t]{2}{*}{ One } & 1. & 1 & 0 & 1 \\
\hline & 2. & 1 & 0 & 1 \\
\hline \multirow[t]{2}{*}{ Two } & 1. & 1 & 0 & 1 \\
\hline & 2. & 1 & 0 & 1 \\
\hline \multirow[t]{2}{*}{ Three } & 1. & 1 & 0 & 1 \\
\hline & 2. & 4 & 0 & 4 \\
\hline \multirow[t]{2}{*}{ Four } & 1. & 4 & 0 & 4 \\
\hline & 2. & 1 & 0 & 1 \\
\hline \multirow{3}{*}{ Five } & 1. & 1 & 0 & 1 \\
\hline & 2. & 1 & 0 & 1 \\
\hline & 3. & 4 & 0 & 4 \\
\hline \multirow[t]{2}{*}{ Six } & 1. & 1 & 0 & 1 \\
\hline & 2. & 3 & 0 & 3 \\
\hline Seven & 1. & 1 & 0 & 1 \\
\hline \multirow[t]{2}{*}{ Eight } & 1. & 3 & 0 & 3 \\
\hline & 2. & 5 & 0 & 5 \\
\hline \multirow{3}{*}{ Nine } & 1. & 5 & 0 & 5 \\
\hline & 2. & 1 & 0 & 1 \\
\hline & 3. & 1 & 0 & 1 \\
\hline Sum & & 40 & $\mathbf{0}$ & 40 \\
\hline
\end{tabular}

As Table 15 shows, out of a total of 40 items in Section G, all of them are non-tasks and none of them qualifies as a task. Table 16 presents the percentages of tasks and non-tasks in the Section G of the textbook (The Pronunciation Section).

TABLE 16:

THE PERCENT AGES OF TASKS AND NON-TASKS IN SECTION G

The Percentage of Non-Tasks in Section G

The Percentage of Tasks in Section $G$

The number of tasks and non-tasks in the Section H of the textbook (The Vocabulary Review Section) is presented in Table 17.

TABLE 17:

THE NUMBER OF TASKS AND NON-TASKS IN SECTION H

\begin{tabular}{|l|l|l|l|}
\hline Lesson & Non-Task & Task & Total \\
\hline One & 8 & 0 & 8 \\
\hline Two & 10 & 0 & 10 \\
\hline Three & 0 & 10 & 10 \\
\hline Four & 0 & 6 & 6 \\
\hline Five & 8 & 0 & 8 \\
\hline Six & 8 & 0 & 8 \\
\hline Seven & 0 & 9 & 9 \\
\hline Eight & 10 & 0 & 10 \\
\hline Nine & 9 & 0 & 9 \\
\hline Sum & $\mathbf{5 3}$ & $\mathbf{2 5}$ & $\mathbf{7 8}$ \\
\hline
\end{tabular}

As Table 17 shows, of a total of 78 items in Section H, 25 items are tasks and 53 items are non-tasks.

Table 18 presents the percentages of tasks and non-tasks in the Section H of the textbook (The Vocabulary Review Section).

TABLE 18:

THE PERCENT AGES OF TASKS AND NON-TASKS IN SECTION H

\begin{tabular}{|l|l|}
\hline The Percentage of Non-Tasks in Section H & $67.9 \%$ \\
\hline The Percentage of Tasks in Section H & $32 \%$ \\
\hline
\end{tabular}

Table 19 presents the total number of tasks and non-tasks in different sections of the textbook. 
TABLE 19:

THE TOTAL NUMBER OF TASKS AND NON-TASKS IN THE TEXTBOOK

\begin{tabular}{|l|l|l|l|}
\hline Section & Total Number of Non-Tasks & Total Number of Tasks & Total Number of Items \\
\hline A & 118 & 0 & 118 \\
\hline C & 0 & 182 & 182 \\
\hline D & 324 & 16 & 340 \\
\hline E & 105 & 37 & 142 \\
\hline F & 5 & 13 & 18 \\
\hline G & 40 & 0 & 40 \\
\hline H & 53 & 25 & 78 \\
\hline Sum & $\mathbf{6 4 5}$ & $\mathbf{2 7 3}$ & $\mathbf{9 1 8}$ \\
\hline
\end{tabular}

Table 19 shows that out of a total of 918 items in the different sections throughout the textbook, most of them (645 items) are non-tasks and only 273 items are tasks. The total percentages of tasks and non-tasks in the textbook are presented in Table 20.

TABLE 20:

THE TOTAL PERCENTAGES OF TASKS AND NON-TASKS IN THE TEXTBOOK

\begin{tabular}{|l|l|}
\hline Total Percentage of Non-Tasks in Textbook & $70.2 \%$ \\
\hline Total Percentage of Tasks in Textbook & $29.7 \%$ \\
\hline
\end{tabular}

\section{DisCUSSION \& CONCLUSION}

The first research question was how effective tasks are in the learning of English from the perspective of Iranian high school students. $80.7 \%$ of the responses indicated that the majority of the students considered tasks to be effective in the learning of English and $8.4 \%$ of the responses rated them as being ineffective.

The second research question was how effective textbook activities are in the learning of English from the perspective of Iranian high school students. Only $20.7 \%$ of the responses rated the actual activities in the textbook as being effective and $62.7 \%$ of the responses demonstrated that the majority of the students considered them to be ineffective.

The third research question was about the percentages of tasks and non-tasks in the textbook. The analysis of the different sections of the textbook showed that a large share of the textbook (70.2\%) is allocated to exercises (non-tasks), and only a small percentage of the textbook constitutes tasks (29.7\%). The results of the analysis of the questions in the questionnaire were in sharp contrast with the results of the textbook analysis; i.e. while the majority of the students preferred tasks over the actual textbook activities, a low percentage of the textbook is dedicated to tasks.

Also, as the learners' responses showed, tasks provide them with greater time to communicate than the actual activities in their textbooks, most of which do not call for group work. Meaningful production practice has a number of benefits for learners such as enhancing their fluency by increasing automaticity through practice which may cause students to attend more to relevant information, notice gaps in their own production, test their hypothesis, and talk about language and collaboratively solve problems (Saville-Troike, 2006). According to Swain (1985, as cited in Richards \& Rodgers, 2001), having opportunities for the productive use of language is essential for students. Tasks provide both the input and output necessary for successful language acquisition to take place.

Plough and Gass (1993, as cited in Richards \& Rodgers, 2011) believe that the negotiation of meaning, which becomes possible through the using of tasks, helps focus the learner's attention on some aspect of the utterance produced by the learner, i.e. grammar, vocabulary, pronunciation, etc. which requires modification. This is in line with the students' high rating of tasks as being effective in enabling them to produce grammatically correct sentences, improving their vocabulary knowledge, and their pronunciation.

With regard to fluency, a fairly high percentage of responses (83\%) rated tasks to be effective in improving learners' fluency, as opposed to $21 \%$ for the actual textbook activities. This could be because all of the sample tasks presented in the questionnaire involved interaction. The poor rating of the actual textbook activities could be because the majority of them do not encourage the students to interact with each other. The analysis of Section D (Speaking Out) revealed that over $95 \%$ of the activities in this section are exercises (non-tasks) that are concerned with grammar rather than meaning-focused communication and developing fluency. Through the use of intermittent phases of focus-on-form and focus-on-communication during the performance of tasks, learners can develop effective fluency. They can move their IL forward in the focus-on-form phase and develop effective fluency by being forced to communicate in real-time during the focus-on-communication phase (Salmani-Nodoushan, 2008).

A high percentage of the responses (85\%) rated tasks as being effective in promoting accuracy, as opposed to $29 \%$ for the actual textbook activities. According to Schachter (1974, as cited in Salmani-Nodoushan, 2008), less proficient L2 learners often use avoidance and communication strategies, which may reduce the pressure on their partiallyefficient interlanguage to change. This can promote accuracy.

According to Widdowson (1989), time pressure to communicate in real-time will push the learners to rely on the lexical mode of processing rather than the syntactic mode. This is because the syntactic mode is often employed when 
the emphasis is on accuracy. This implies that, as $77 \%$ of the responses have rated, as opposed to $38 \%$ for textbook activities, tasks can be effective in improving the vocabulary knowledge of learners.

Employing public speaking tasks such as presentation and debate tasks creates an environment in which all four language skills of listening, speaking, reading, and writing can be improved. Speaking plays an important role in both of these tasks. Peer evaluation can help improve the students' listening skill, particularly during debates provided that participants are required to take notes and give responses to the speeches delivered by their partners. Moreover, since students will have to skim, scan, and read specific materials in depth to be able to find relevant information to use in their presentations and debates, they will improve their reading and writing skills while they are preparing themselves for the task through taking notes, completing argumentative essays, and preparing for oral presentations, students improve their writing skill.

The findings of this study confirm Rahimi and Hassani's (2012) findings, where students did not perceive high school textbooks as valuable learning sources. In their study, they found a positive correlation between Iranian EFL learners' attitudes towards their textbooks and their attitudes towards learning English as a foreign language. As the present study showed, the negative attitudes of the students towards their textbook activities and the wide difference between their preferences and the actual content of the textbook had a negative impact on their level of motivation for learning English. Evidently, students often develop negative attitudes towards learning English as a foreign language as a result of the lack of stimulating and authentic materials and tasks (Richards, 2001). Authentic materials are meaningful to students, and engage them personally. Such materials also increase their intrinsic motivation.

Since for Iranian EFL learners textbooks are the primary source of first-hand experience with English (Azizifar et al, 2010), high school English textbooks should be revised, and they should provide students with opportunities to interact with the materials that motivate them to learn English (Gibbs, 1992, as cited in Rahimi \& Hassani, 2012). The study also revealed that students did not find the actual textbook activities as being effective in the development of their four language skills. These findings confirm the findings of those studies that have discussed that language skills and components such as reading, listening, speaking, writing, vocabulary, grammar, and pronunciation are poorly developed and presented in Iranian EFL textbooks (e.g. Ketabi \& Talebinezhad, 2009), even though the findings of most of these studies are based on teachers' ideas and perceptions. Textbook designers could increase the number of tasks in various sections of high school English textbooks so that they become more valuable sources of learning by being more in line with what students find to be motivating and useful.

The results of this study suggest that there are great mismatches between the actual content of the textbook and what the students perceive to be motivating and useful in the learning of English; i.e. the use of tasks, the percentage of which was shown to be insufficient in the actual textbook. The results of this research can be useful to textbook designers if they are willing to consider the perceptions of learners in the possible future revisions of high school textbooks. It can also give language teachers at high school level some insights about what their students perceive to be more effective in the learning of English, how they would like to go about learning the language, and to what aspect of language they need to allocate more time in order to compensate for the shortcomings of the textbook. The results of the study would still be valid in the event of high school textbooks undergoing revision in the future, since the results reflect the preferences of learners which could be compared to the content of the revised textbooks, or may even be taken into consideration in future revisions.

\section{APPENDiX A. The ENGLISH VERSION OF THE QUESTIONNAIRE}

Below, you see some samples of tasks that can be included in your English textbook and be used in the classroom. Please read about these sample tasks and share your opinion about them by answering the relevant questions.

Task 1: Think about your favorite season. Work individually for 5 minutes and make a list of all the reasons why you like that particular season. (For example, I like spring because I like flowers.) Now, work in groups and explain your reasons to your group members. If they like a different season, try to describe the negative aspects of their favorite season. Then, your teacher will talk to the class about his favorite season and you will have the opportunity to agree or disagree with him.

Task 2: Read the following text for 5 minutes. Discuss with your group members whether you found the topic interesting and why. Make a list of the things you liked about the text. Then, discuss in your group about whose list includes more interesting points about the text. Ask him to read the list out loud to the class. The teacher and the rest of the students will comment on the list.

Let's think you are in a foreign country. If you don't know the language of that country, you may have a lot of problems. Here is the story of a Frenchman who was traveling in the United States. One day he was eating in a restaurant and wanted to order some mushrooms. Because he didn't know English, he asked for a pencil and paper and carefully drew a picture of a mushroom. But his drawing was not very good. The waiter looked at his drawing and went away. He returned in about twenty minutes with a large umbrella.

Task 3: Your teacher will give each of your group members a card, which includes statements beginning with "Find someone who......" as in "Find someone who likes tennis." Walk around the classroom and try to find someone who 
agrees with that statement. Next, pair up with that person and ask him to explain to you why he agrees or disagrees with the stated action. Make a list of his reasons and report them to your teacher.

Task 4: Ask one of your group members to walk out of the classroom. Choose an object (such as your pen) and hide it somewhere in the classroom. After your friend is back, he should try to find the hidden object by telling your group members where he guesses / thinks / believes the object is hidden. For example "I think / guess that the pen is in Ali's bag."

Task 5: Each student in your group will be given two pictures depicting a part of a story involving a character who is doing different things in each picture. Work individually and write a few sentences about what the character is doing in your picture. Then, share your sentences with your partners and together decide what the proper order for the story is. Elect a student from among your group who can recite the story orally well. The teacher and the other students will comment on the story.

1. How effective can such tasks be in making language learning enjoyable?

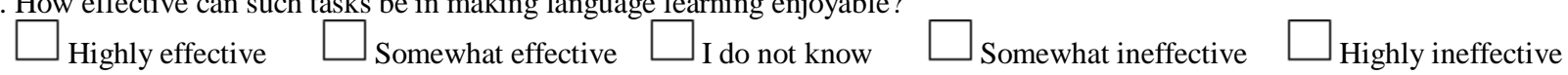

2. How effective can such tasks be in engaging you in learning English?

$\square_{\text {Highly effective }} \quad \square_{\text {Somewhat effective }} \square_{\text {I do not know }} \quad \square_{\text {Somewhat ineffective }} \square_{\text {Highly ineffective }}$

3. How effective can such tasks be in increasing your motivation to learn English?

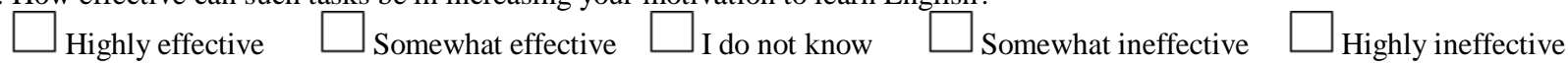

4. How effective can such tasks be in causing you to cooperate with your group members to perform the task?

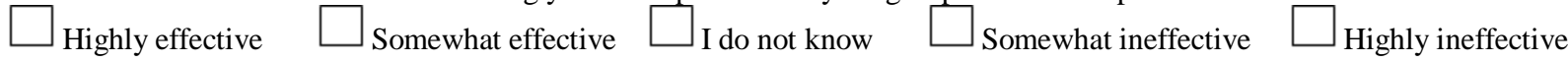

5. How effective can such tasks be in improving your accuracy in producing grammatically correct sentences?

$\square$ Highly effective $\square$ Somewhat effective $\quad \square_{\text {I do not know } \quad \square}$ Somewhat ineffective $\quad \square_{\text {Highly ineffective }}$

6. How effective can such tasks be in improving your fluency in speaking English?

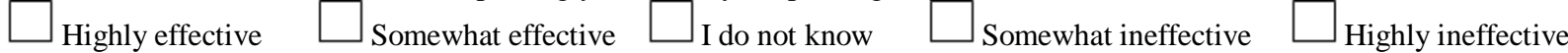

7. How effective can such tasks be in improving your vocabulary knowledge?

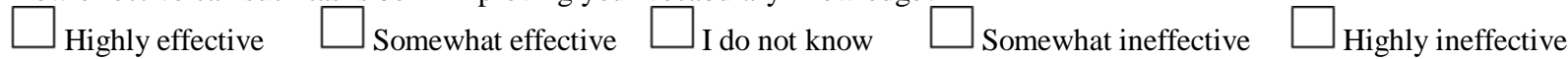

8. How effective can such tasks be in improving your pronunciation?

$\square$ Highly effective $\quad \square$ Somewhat effective $\square_{\text {I do not know }} \quad \square_{\text {Somewhat ineffective }} \square_{\text {Highly ineffective }}$

9. How effective can such tasks be in improving your language skills (reading, writing, listening, speaking)?

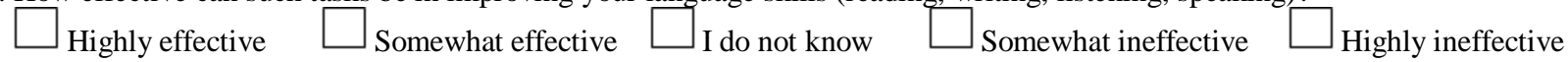

10. How effective can such tasks be in providing you with the opportunity to communicate with others?

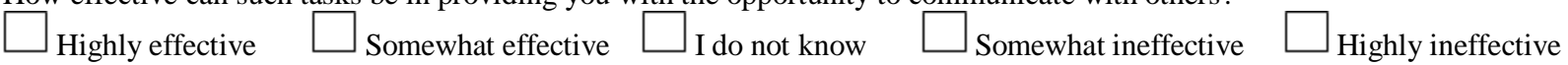

The following questions are about the actual activities in your English textbook.

11.How effective are the actual activities in your textbook in making language learning enjoyable?

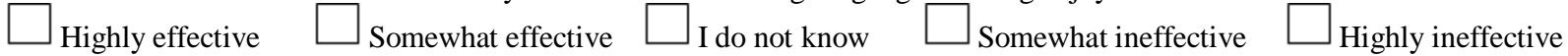

12. How effective are the actual activities in your textbook in engaging you in learning English?

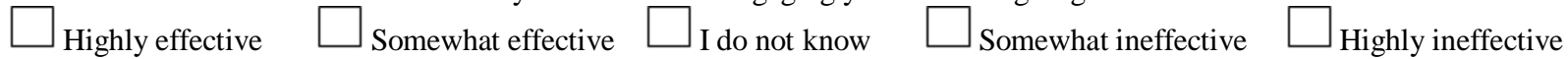

13. How effective are the actual activities in your textbook in increasing your motivation to learn English?

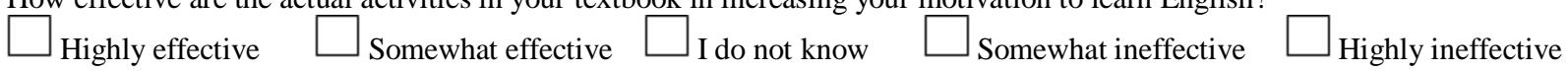

14. How effective are the actual activities in your textbook in encouraging you to work in groups?

$\square_{\text {Highly effective } \quad \square}$ Somewhat effective $\quad \square_{\text {I do not know } \quad \square}$ Somewhat ineffective $\square$ Highly ineffective

15. How effective are the actual activities in your textbook in improving your accuracy in producing grammatically correct sentences?

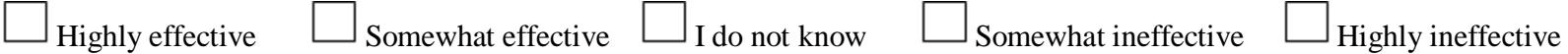

16. How effective are the actual activities in your textbook in improving your fluency in speaking English?

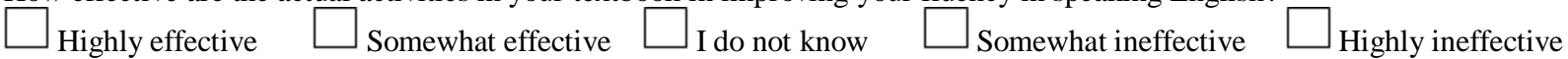

17. How effective are the actual activities in your textbook in improving your vocabulary knowledge?

$\square_{\text {Highly effective } \quad \square}$ Somewhat effective $\square_{\text {I do not know }} \quad \square_{\text {Somewhat ineffective }} \square_{\text {Highly ineffective }}$

18. How effective are the actual activities in your textbook in improving your pronunciation?

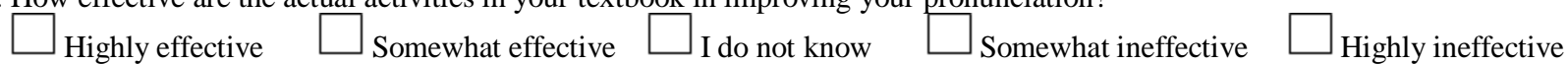

19. How effective are the actual activities in your textbook in improving your language skills (reading, writing, listening, speaking)?

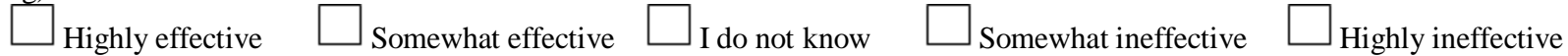
20. How effective are the actual activities in your textbook in providing you with the opportunity to communicate with others?

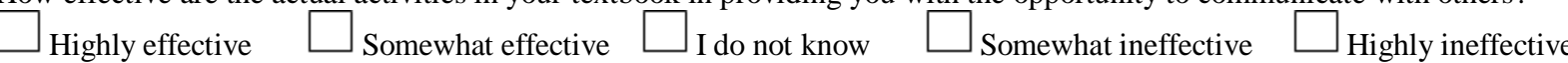




\section{REFERENCES}

[1] Amiryousefi, M., \& Ketabi, S. (2011). Anti-textbook arguments revisited: A case study from Iran. Procedia Social and Behavioral Sciences, 15, 215-220.

[2] Azizifar A., Koosha, M., \& Ahamd R. (2010). An analytical evaluation of Iranian high school ELT textbooks from 1970 to the present. Procedia Social and Behavioral Sciences, 3, 36-44.

[3] Brown, H.D. (2006). Principles of language learning and teaching. White Plains, NY: Longman.

[4] Csikszentmihalyi, M. (1991). Flow: The psychology of optimal experience. New York: Harper Collins.

[5] Dietz, C. (2004). Mihaly Csikszentmihalyi's theory of flow. Retrieved December 10,2011 from http://www.teachingexpertise.com/articles/mihaly-csikszentmihalyis-theory-of-flow-1674

[6] Ellis, R. (2003). Task-based language learning and teaching. Oxford: Oxford University Press.

[7] Finch, E. (2007). Baduk and second language learning: Effortful study and balanced flow. Studies in British and American Language and Literature, 85, 231-249.

[8] Ketabi, S., \& Talebinezhad, M. (2009). Socio-cultural patterns of Iranian EFL textbooks in arousing students' motivation to do research. Journal of Language Teaching Skills, 4, 41-69.

[9] Liao, L. (2006). A flow theory perspective on learner motivation and behavior in distance education. Distance Education, 27, 45-62.

[10] McGrath, I. (2002). Materials evaluation and design for language teaching. Edinburgh: Edinburgh University Press.

[11] Nassaji, H., \& Fotos, S. (2010). Teaching grammar in second language classrooms: Integrating form-focused instruction in communicative context. Routledge.

[12] Rahimi, M., \& Hassani, M. (2012). Attitude towards EFL textbooks as a predictor of attitude towards learning English as a foreign language. Procedia Social and Behavioral Sciences, 31, 66-72.

[13] Rahimi, M., \& Nabilou, Z. (2009). Globalization and EFL curriculum reform in Iran: Challenges and opportunities. Journal of Technology of Education, 3, 115-124.

[14] Richards, J.C. (2001). The role of textbooks in a language program. Cambridge: Cambridge University Press.

[15] Richards, J. C., \& Rodgers, T.S. (2001). Approaches and methods in language teaching. Cambridge: Cambridge University Press.

[16] Salmani-Nodoushan, M, A. (2008). A framework for task-oriented language instruction. I-Manager's Journal on School Educational Technology, 3(3), 5-16.

[17] Saville-Troike, M. (2006). Introducing second language acquisition. Cambridge: Cambridge University Press.

[18] Tomlinson, B., Dat, B., Masuhara, H., \& Rubdy, R. (2001). EFL courses for adults. ELT Journal, 55(1), 80-101.

[19] Widdowson, H.G. (1989). Knowledge of language and ability for use. Applied Linguistics, 10(2), 128-137.

Mohsen Sa'di Khosroshahi: M.A. student in Teaching English as a Foreign Language (TEFL), studying at University of Tabriz, Iran. He got his B.A. in TEFL at Shahid Madani Azarbaijan University, Iran.

Farahman Farrokhi: The Dean of Faculty at Faculty of Persian literature \& foreign languages at University of Tabriz. From 2010 onwards he has been the Associate Professor at the University of Tabriz. He got his B.A. from Allameh Tabatabaii UniversityTehran, his M.A. from Tarbiat Modarres University - Tehran, and his Ph.D. from University of Leeds - UK. He is the supervisor of the thesis based on which this paper was written. 